\title{
Mastoidectomy: anatomical parameters x surgical difficulty
}

\author{
Mastoidectomia: parâmetros anatômicos x dificuldade cirúrgica \\ Anastácio Rodrigues Pereira Júnior', Sebastião Diógenes Pinheiro², José Daniel Vieira de Castro ${ }^{3}$, João Aragão Ximenes Filho4,
Marcos Rabelo de Freitas ${ }^{5}$.
}

1) Post Graduated in Otorhinolaryngology. Otorhinolaryngologist from SESI.

2) Ph.D. in Otorhinolaryngology by Medical School from Universidade de São Paulo. Chief of Service from Otorhinolaryngology from Medical School from Universidade Federal do Ceará.

3) Ph.D. in Clinical Medicine by the Medical School from Ribeirão Preto from Universidade de São Paulo. Associate Professor from the Clinical Medicine from Medical School from Universidade Federal do Ceará.

4) Ph.D. in Otorhinolaryngology by Medical School from Universidade de São Paulo. Associate Professor from the Departament of Surgery from Medical School of Universidade Federal do Ceará.

5) Ph.D. in Surgery by Universidade Federal do Ceará. Post Doctorate in the Otologic Group from Piacenza, Italy. Associate Professor in Otorhinolaryngology by Medical School from Universidade Federal do Ceará.

Institution: Service from the Otorhinolaryngology Academic Hospital Wálter Cantídio from Universidade Federal do Ceará Fortaleza / CE - Brazil

Mailling Adress: Anastácio Rodrigues Pereira Júnior - Rua Almirante Rufino, 1089, Apto 403 Torre I - Bairro: Vila União - Fortaleza / CE - Brazil - Zip Code: 60420-075

- Telephone: (+55 85) 3089-5151 - E-mail: anastaciorpjr5@yahoo.com.br

Article received in June 1st of 2011. Article approved in June 25th of 2011.

\section{SUMMARY}

Introduction: The lowered temporal meninges and/ or anterior sigmoid sinus are contiditions that can determine surgical difficulties in performing mastoidectomy.

Objective: To correlate in the tomography the extent of the prolapse of the sigmoid sinus and of temporal meninges with the surgical difficulty in the mastoidectomy.

Method: The tomographic measurements of prolapse sigmoid and of temporal meninges were correlated with the presence or non-presence of the surgical difficulty observed during the mastoidectomy procedure in patients with ostomatoiditis chronic $(n=30)$.

Form of study: Contemporary cohort transverse.

Results: In 10 patients were observed surgical difficulty distributed as: due to prolapse of the sigmoid sinus $(n=2)$ or temporal meninges prolapse $(n=7)$ or both $(n=1)$. In patients in which the surgical difficulty was due to sigmoid sinus prolapse, the tomography distance of the anterior border of the sigmoid sinus to posterior wall of external auditory canal was lower than $9 \mathrm{~mm}$. In patients in which surgical difficulty was due to temporal meninges prolapse, the tomographic distance to the upper plane of the petrous bone was $7 \mathrm{~mm}$. Conclusion: The computerized tomography distance between the temporal meninges and the upper plane of the petrous bone $7 \mathrm{~mm}$ and the distance of the anterior border of the sigmoid sinus to posterior wall of external auditory canal was lower than $9 \mathrm{~mm}$ are predictive to the surgical difficulties to perform mastoidectomy.

Keywords: tomography, temporal bone, meninges.

\section{RESUMO}

Introdução: A meninge temporal rebaixada e o/ou seio sigmoide anteriorizado são condições que podem determinar dificuldades cirúrgicas na realização da mastoidectomia.

Objetivo: Correlacionar a medida do prolapso do seio sigmoide e da meninge temporal na tomografia com a dificuldade cirúrgica na mastoidectomia.

Método: As medidas tomográficas de prolapso sigmóideo e da meninge temporal foram correlacionadas com presença ou não de dificuldade cirúrgica observados durante o procedimento mastoidectomia de pacientes com otomastoidite crônica $(n=30)$.

Forma de estudo: Coorte contemporânea com corte transversa.

Resultados: Em 10 pacientes, observou-se dificuldade cirúrgica assim distribuída: devido ao prolapso do seio sigmoide $(n=2)$ ou prolapso da meninge temporal $(n=7)$ ou ambos $(n=1)$. Nos pacientes cuja dificuldade cirúrgica foi devido ao prolapso do seio sigmoide, a distância na tomografia da borda anterior do seio sigmoide à parede posterior do canal auditivo externo foi menor que $9 \mathrm{~mm}$. Nos pacientes cuja dificuldade cirúrgica foi devido ao prolapso da meninge temporal, a distância tomográfica desta ao plano superior do osso petroso foi $7 \mathrm{~mm}$.

Conclusão: A distância na tomografia computadorizada entre a meninge temporal e o plano superior do osso petroso $7 \mathrm{~mm}$ e uma distância do bordo anterior do seio sigmoide à parede posterior do canal auditivo externo inferior a $9 \mathrm{~mm}$ são preditivos de dificuldades cirúrgicas durante a mastoidectomia. Palavras-chave: tomografia, osso temporal, meninges. 


\section{INTRODUCTION}

The temporal boné is a frequente site of surgical intervention. Mastoidectomy be it for resolution from the chronic infectious process or as a initial part from access to the cochlear implant, is among the routine surgical procedures. Among the important anatomical structures related with the mastoid, stand out the temporal lobe and the sigmoid sinus (SS), because of the difficulty of surgical approach that the anatomical variations of such structures can determine (1). Is known that the middle cerebral fossa relies under a thin layer of bone, o tegmen tympani, forming the ceiling from the tympanic cavity. In general is at the same level or just slightly below the upper edge of the petrous bone. However, in a few individuals, the same is much more lower, inside the mastoid cavity. But the sigmoid sinus, that is normally located in a position more to the posterior side, can eventualy, be located more anteriorly, projected for more to the inside of the mastoid cavity, the condition called procidentia (2).

The normal variants from the temporal bone constitute a frequent problem during the realization from the surgical procedures of the mastoid. The procidentia from the lateral sinus at the level from the sigmoid portion reduces the space to post auricular approach from the mastoid antrum. The meninge from the lowered temporal lobe interfere for the surgical access to the attic and increases the risk of formation from cerebrospinal fluid leak. The prediction from these conditions must be established before the surgery with studies of images from CT of high resolution in means of perform a surgical procedure safe and efficient (3). The objective from the this study is to correlate the tomographic findings of

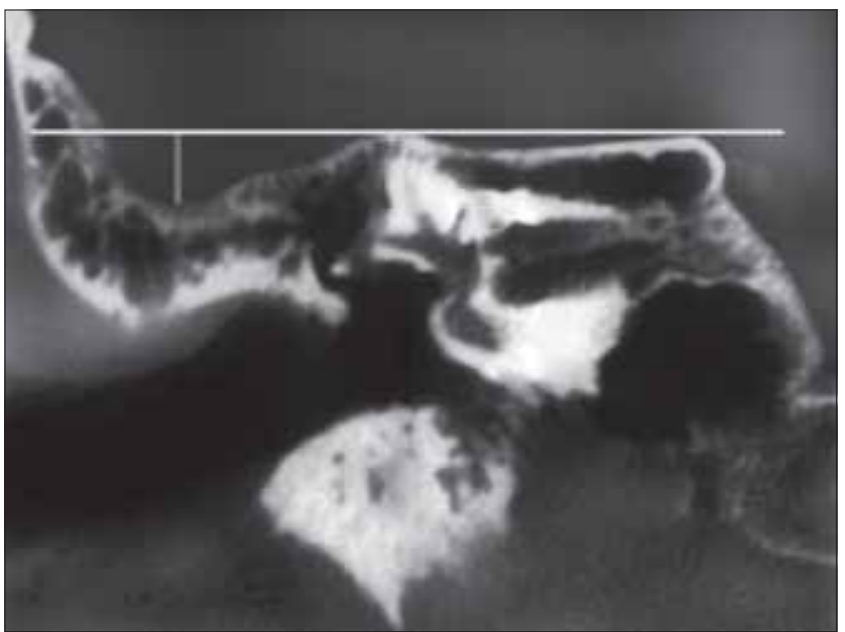

Image 1. Tomographic image coronal cut showing the measure from the meningeal prolapse. position from the sigmoid sinus (SS) and from the meninge of the temporal lobe (TL) with degree of technical difficulty in the performance from the mastoidectomy.

\section{METHOD}

Participated from the study thirty consecutives patients, being seventeen male and thirteen female, with indication of mastoidectomy for the solving from the chronic infectious process from the temporal bone, with a cholesteatomatous nature or not, from both sex, without history of a previous otologic surgical procedure, and without changes craniofacial. All performed the TC from the temporal bone in this hospital institution, previously to the surgical intervention, in the coronal and axial plans with cuts of $1,5 \mathrm{~mm}$ of density, spacing of $1 \mathrm{~mm}$ and $120 \mathrm{KV} /$ $220 \mathrm{mAs}$ of power. The study was approved by the ethical committee from that institution under the protocol 083.10.07

The height of the meninx from the temporal lobe in the mastoid corresponded to the measure from distance from it to a line that tangent to the upper edge of the petrous bone. The measures were made directly in the film, with millimiter ruler, in the coronary cut in plane of the internal auditory canal, and converted to the appropriated scale (Image 1). The position from the SS corresponded to the lower distance from the anterior edge to the posterior wall of the auditory canal, as noted in the axial tomographic image, on the plane from the bone portion from the auditory tube (Image 2).

All patients submitted to the mastoidectomy open or closed technique, by two surgeons with great experience

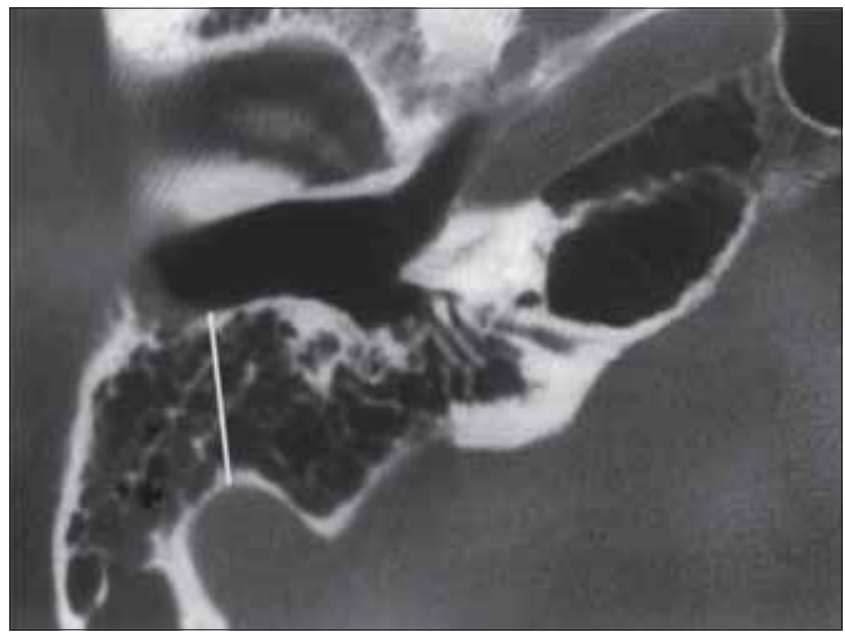

Image 2. Tomographic image, axial cut, showing the distance of the sigmoid sinus and the anterior edge from the external auditory canal. 
in the realization of this kind of surgery. The dissection was extended until reach the adequate exposure from the mastoid antrum, the side and attic semi-circular canal. The procedures were considered technically hard when had the need for deviaton from the tegmen timpani or from SS. If those structures does not impose any obstacle to the approach of the antrum and from the attic, was classified without technical difficulty. Was used the exact test of Fisher in the statistical processing from the available data.

\section{RESULTS}

From the thirty participants from the study, there was seventeen men and thirteen women. The age variated from 12 to 317 years (Average of 24 years ). Thirteen patients had cholesteatoma (43,3\%) and the others, chronic otitis media without cholesteatoma. There was need of mastoidectomy open technique in eight participants, corresponding to $26,6 \%$ of cases.

Altogether ten patients, corresponding to $33,3 \%$ of the total, presenting surgical difficulty, so distributed: two because the presence of procidentia from SS, seven because of existence of procidentia in the meninx from the temporal lobe and one because of both conditions simultaneously. The distance from SS to the posterior wall from CAE ranged from $4,7 \mathrm{~mm}$ to $18,7 \mathrm{~mm}(11,8 \mathrm{~mm} \pm 2,7)$ (Table 1). The tomographic measure from the height of the meninx in the temporal lobe in the mastoid ranged from zero to a maximum of $13 \mathrm{~mm}(5,57 \mathrm{~mm} \pm 3,2$ ) (Table 1).

In all cases of surgical difficulty because of the procidentia from the meninx of the temporal lobe, the measure finded was equal or superior to seven millimeters. In the three situations that was found surgical difficulty because the previous presence from the SS, the value from the measure of this for the external auditory canal (EAC) was inferior to nine millimeters.

The statistical analysis from the correlation between the tomographic measures obtained X the existence or not from the surgical difficulty by means of the exact test of Fisher, obtained a difference statistically highly significant for the surgical difficulty for the tomographic measure from the height of the meninx from the temporal lobe in the mastoid equal or superior to seven millimeters $(\mathrm{P}<0,001)$, and for the tomographic difference from the distance of the sigmoid sinus to the external auditory canal lower than nine millimeters $(\mathrm{P}=0,0002)$.

\section{DISCUSSION}

The presence from anatomical variants impose the greatest technical challenge for all otology surgeons during the performance from the mastoidectomy, be it conservative or radical. The lowering from the temporal lobe increases the risk of injury to the dura of the middle fossa and reduces the space for an adequate exposure to the antrum and attic. In the accentuated procidentia may have the need of overthrow of the wall face in the initial stage from the mastoidectomy, even in the conditions which is not formally indicated. The anterior displacement from the SS, on the other hand, favors the injury, well as darkens the visions from the medial areas of the mastoid (4). There are none in the researched medical literature studies that correlate the degree of surgical difficulty in the conventional mastoidectomy with tomographic measures from temporal bones, with emphasis in the sigmoid sinus and from the height from the meninx in the temporal lobe.

BeatTy et al, (5) compared the anatomical measures and the distances from many structures from the temporal bones formalized with those images obtained in the computerized tomography of high resolution. Concluded that the CT from the temporal bones can produce diagnostic images, accurate and highly detailed from the internal auditory canal, vestibule, cochlea, vestibular aqueduct, semicircular canals, ossicles and spaces from the middle ear.

Thomassim et al, (6) performed a retrospective study of 178 trans labyrinthine approaches from the cerebello pontine angle with emphasis for the existence of venous or meningeal prolapsed of the temporal bone. Superficially the access was reduced in $43 \%$ of patients because the existence of the procidentia from the side sinus in 27 cases or the procidentia from the meninx in the temporal lobe in 50 patients. The surgery was technically difficult in 8 patients ( $4,5 \%$ of cases) with procidentia from the side

Table I. Results from the measures (in millimeters) from the distances between the sigmoid sinus and the internal auditory canal and from the lowering of the temporal meninx.

\begin{tabular}{lccccc}
\hline & Maximum value & Minimum value & Average & Standard deviation & Median \\
Lowering from the temporal meninx & 13 & zero & 5,5 & 3,2 & 6 \\
Distance from SS to EAC & 18,7 & 4,7 & 11,8 & 2,7 & 11 \\
\hline
\end{tabular}

Note: SS - Sigmoid Sinus ; EAC - external auditory canal. 
sinus associate with the meningeal procidentia. Numbers substantially inferior than the ones found in the present study (33\%). We believe that such difference is due the not pneumatization in the mastoid from the patients in the present study, all carriers from the chronic otomastoiditis.

In the researched medical literature was observed different criteria, varying from author to author, in the definition of procidentia, whether from the sigmoid sinus than for the height from the temporal lobe. In the study from THOMASSIM was considered the procidentia from SS when the measure from the distance of this to the EAC was inferior than $15 \mathrm{~mm}$, and the existence of procidentia from the meninx from the temporal lobe only when there was $\mathrm{n}$ space between the dura and the superior wall from the EAC. But for TOMURA et al, (7) that investigated the presence of normal anatomic variations in the images from the computed tomography from 650 normal temporal bones, found the anterior sigmoid sinus in only $1,6 \%$ of the cases, much inferior to the present study that was of $10 \%$. By the used criteria by them, the sigmoid sinus was anterior only when limited the posterior wall from the external auditory canal. Our results support evidences that there is surgical difficulty for a procidentia from inferior SS of nine millimeters and that the same way for the lowering from the meninx from the temporal lobe bigger or equal to seven millimeters according to the superior plane from the petrous bone. We believe that the election of criteria that correlate the anatomical measures with degree of surgical difficulties as explained above, has greater application in the daily clinical practice.

JAROSLAW (8) studied the minimal distances between the key structures of 100 normal temporal bones using the computed tomography of high resolution, among them is the distance between the sigmoid sinus and the posterior wall from the EAC. In two studied parameters (distance from the facial nerve to the tympanic ring and the distance from the sigmoid sinus and the posterior wall from EAC) none difference statistically significant was found relating to age or gender..

EkINCE e cols. (9) studied the distances between the important neural and vascular structures in 100 temporal bones from normal individuals, using computed tomography of high resolution. Found that the average distance between the sigmoid sinus and the posterior wall from the EAC was from $13,2 \mathrm{~mm}$. In the present study, performed only in patients with chronic otomastoiditis, that value was of 11,3 $\mathrm{mm}$. Data from literature that support evidences that the pneumatization reduced from the temporal bone is related to the anterior positioning of the sigmoid sinus are conflicting. TURGUT (10) e col. studied 60 adult temporal bones, by images of $\mathrm{x}$-ray, computed tomography and surgical dissection including the otomicroscopic findings, did not obtained differences statistically significant between the degree of pneumatization from the mastoid and the shortest distance between the sigmoid sinus and the external auditory canal. But SHATZ (11) and colleagues compared the measures from the distances of SS and the EACin the group with mastoid completely sclerotic (150 ears) with temporal bones of health individuals and pneumatized mastoid. A significant difference $(p<0,0001)$ was found among the two groups, being the average of distance in patients of $7,8 \pm 1,7 \mathrm{~mm}$, and from control 13,5 $\pm 2,8 \mathrm{~mm}$.

\section{CONCLUSION}

Is expected to have technical difficulties in the performance of mastoidectomy when the tomographic measure from the distance of the sigmoid sinus to the posterior wall from the external auditory canal is inferior to nine millimeters and when the tomographic measure of lowering from the meninx of the temporal lobe according to the superior plane of the petrous bone is equal or superior to seven millimeters.

\section{BibliograpHIC ReFERENCES}

1. Anson BJ, DonaldsonJA. Surgical anatomy of the temporal bone and ear.2nd ed. Philadelphia: WB Saunders; 1973.

2. Weber PC. Iatrogenical complications from cronic ear surgery. Otolaryngol Clin N Am. 2005, 38:711-722.

3. Maniglia AJ, SprencherSC, MegerianCA, Lanzieri C. Inferior mastoidectomy - hypontimpanic approach for surgical removal of glomus jugulare tumors: An anatomical and radiologic study emphasizing distances between critical estrutures. Laringoscope. 1992, 102:407-414.

4. Gangopadhyay K, McArthur PD, Larsson SG. Unusual anterior course of the sigmoid sinus: Report of a case review of the literature. The Journal of Laryngology and Otology 1996, 110:984-986.

5. Beatty CW, Suh KW, Harris LD, Reese DF. Comparative study using computed tomographic Thin-section zoom reconstructions and anatomic macrosections of the temporal bone. Ann Otol. 1981, 90:643-649.

6. Thomassim JM, Braccini F, Roche P, Pellet W. Voie translabynthique et procidences veineuses (Golfo de la jugulaire et sinus lateral). Rev Laryngol Otol Rhinol. 1999, 120:83-87.

7. Tomura N, Sashi R, Kobayashi M, Hirano H, Hashimoto 
M, Wataray J. Normal variations of the temporal bone on hight-Resolution CT: Their incidence and clinical significance. Clinical Radiology 1995, 50:144-148.

8. Jaroslaw W. Minimal distance between temporal bone structures and their mutual correlations. Med Sci Monit. 2002, 8(2):80-82.

9. Ekinci G, Koç A, Baltacioglu F, Veyseller B, Altintas O, Han T. Temporal Bone Measurements on Hight-Resolution Computed Tomography. The Journal of Otolaryngology. 2004, 33:387-389.
10. Turgut S, Tos M. Correlation between temporal bone pneumatization, location of lateral sinus and length of the mastoid process. The Journal of Laryngology and Otology 1992,106:485-489.

11. Shatz A, Sadé J. Correlation between mastoid pneumatization and position of the lateral sinus. Ann Otol Rhinol Laryngol. 1990, 99:142-1. 